\title{
TRANSNEURONAL AND PERIPHERAL MECHANISMS FOR THE INDUCTION OF MOTOR NEURON SPROUTING ${ }^{1}$
}

\author{
SHLOMO ROTSHENKER ${ }^{2}$
}

Department of Anatomy and Embryology, Hebrew University Medical School, Jerusalem, Israel

Received January 13, 1982; Revised March 31, 1982; Accepted May 13, 1982

\begin{abstract}
After injury to the nerve to one cutaneous pectoris muscle of the frog, the intact nerve to the contralateral muscle sprouts and forms additional synaptic connections with already innervated muscle fibers. It has been suggested (Rotshenker, S. (1979) J. Physiol. (Lond.) 292: 535-547; Rotshenker, S., and F. Reichert (1980) J. Comp. Neurol. 193: 413-422) that axotomy initiates a signal for sprouting in the injured neurons that is transferred transneuronally across the spinal cord to intact motor neurons. The present study was designed to test the hypothesis that axotomy initiates the signal for sprouting by interfering with some trophic signaling between the injured neurons and denervated muscle. Colchicine therefore was applied to the nerve to the left muscles to inhibit axonal transport on whose integrity trophic interactions depend. Consequently, supernumerary innervation developed in contralateral right intact muscles much the same as after axotomy. Surprisingly, axons that were exposed to the drug also sprouted and formed synapses. Furthermore, the sprouting response of axons that were exposed to the drug also was produced in nerve fibers that were separated from their cell bodies. These results suggest two ways in which colchicine may produce sprouting and synapse formation and thereby suggest two mechanisms by which motor neurons may be induced to sprout: $(a)$ transneuronally, by presenting growth stimuli to their cell bodies and central processes in the central nervous system and $(b)$ by presenting growth stimuli to their peripheral extensions.
\end{abstract}

Previous studies (Rotshenker and McMahan, 1976; Rotshenker, 1979; Rotshenker and Reichert, 1980) have shown that injury to the nerve to one cutaneous pectoris muscle of the frog induces the intact motor neurons that innervated the homologous muscle on the opposite side to sprout and form synaptic connections with already innervated muscle fibers. As a consequence, some muscle fibers innervated by a single motor neuron became polyneuronally innervated. Alterations in the synaptic connectivity of innervated targets following denervation of contralateral homologous regions were reported recently in the motor (A. Elizalde, M. Huerta, and E. Stefani, manuscript in preparation; Steinbach, 1981), autonomic (Case and Matthews, 1980), and central (Hoff et al., 1981) nervous systems (see "Discussion").

\footnotetext{
${ }^{1}$ I am grateful to F. Reichert and G. Ring for their participation in some of the experiments. I thank Drs. M. Letinsky and D. Purves for their most valuable comments during the preparation of the manuscript and Miss B. Tova and S. Solomon for their technical assistance. This study was supported by National Institutes of Health, Muscular Dystrophy Association, and Dysautonomia Foundation grants.

${ }^{2}$ To whom correspondence should be addressed at Department of Anatomy and Embryology, Hebrew Universily Medical School, Jerusalem, P.O.B. 1172, Israel.
}

Prior experiments in the frog cutaneous pectoris muscles (Rotshenker, 1979; Rotshenker and Reichert, 1980) led to the suggestion that axotomy initiates a signal for sprouting and synapse formation in the injured nerve cells that is transferred across the spinal cord to the responding motor neurons. A possible mechanism by which axotomy could initiate such a signal is interference with some trophic interaction between the damaged nerve and the denervated muscle (e.g., by preventing the supply of a trophic substance from the target tissue to the cell bodies of the innervating neurons). A similar mechanism was suggested to be involved in producing retrograde postaxotomy changes, such as chromatolysis and the loss of afferent input to axotomized nerve cells (see reviews by Grafstein and McQuarrie, 1978; Purves and Nja, 1978). One of the experimental paradigms leading to this notion was the application of colchicine to nerve fibers to inhibit axonal transport whose integrity is believed to be essential for the maintenance of trophic interactions. For example, colchicine produced chromatolysis in and loss of afferent input to nerve cells whose axons were exposed to the drug (Pilar and Landmesser, 1972; Cull, 1975; Purves, 1976). Therefore, I examined the extent to which colchicine would imitate axotomy in 
producing transneuronal sprouting and synapse formation.

The data presented in this report show that the application of colchicine to the nerve of one cutaneous pectoris muscle produces supernumerary innervation in the opposite muscle much the same as contralateral axotomy. Surprisingly, however, supernumerary innervation developed also in the muscle whose own nerve was exposed to colchicine. The delay with which the polyneuronal pattern of innervation developed differed between the two muscles, with a short interval on the treated side (2 to 3 days) and a longer one on the opposite side (2.5 to 3 weeks). Furthermore, the short latency sprouting response of the axons that were exposed to the drug also was produced in nerve fibers that were separaled from their cell bodies. These results suggest two ways in which colchicine may produce sprouting and synapse formation and thereby suggest two mechanisms by which the cutaneous pectoris motor neurons may be induced to sprout: (a) transneuronally, by presenting growth stimuli to their cell bodies and central processes in the central nervous system and $(b)$ by presenting growth stimuli to their peripheral extensions. Brief reports of some of the findings were given previously (Rotshenker, 1980, 1981).

\section{Materials and Methods}

Preparation. Rana pipiens frogs, 5 to $8 \mathrm{~cm}$ in body length, were fed beef liver and kept at room temperature. The two cutaneous pectoris muscles are paired muscles situated in the front of the frog's chest; each is innervated by a separate motor nerve. Most muscle fibers are innervated by a single motor neuron, but $16 \%$ are innervated polyneuronally. All muscle fibers are innervated at a single endplate region which is composed of several elongated gutters. A detailed description of the muscle and its pattern of innervation has been presented previously (Letinsky et al., 1976; Rotshenker and McMahan, 1976; Rotshenker, 1979).

Surgical procedures. Frogs were anesthetized by placing them in water containing $0.1 \%$ tricaine methanesulfonate (Sigma). The nerve to the left cutaneous pectoris muscle was exposed at the axilla. A ring of Orabase (medical protective paste) was made on top of the nerve and a drop of colchicine $(0.010$ to $0.015 \mathrm{M})$ in standard frog Ringer's solution was applied to it. The colchicine and paste were removed after 3 to $5 \mathrm{~min}$, the area was rinsed with Ringer's solution, and the skin was closed with 6-0 sutures. The same procedure was repeated in two control groups with the exception that colchicine was replaced by Ringer's solution or was applied $1 \mathrm{~mm}$ away from the nerve rather than on top of it. In another experimental group, the second spinal nerve that contains the axons innervating cutaneous pectoris muscles was cut close to its exit from the spinal column.

Electrophysiology. The two cutaneous pectoris muscles were removed with their common origin and insertion and their motor nerves. The preparations were bathed in Ringer's solution (116 mM NaCl, $1.8 \mathrm{~mm} \mathrm{CaCl}_{2}$, $2.0 \mathrm{~mm} \mathrm{KCl}, 1 \mathrm{~mm} \mathrm{NaH} \mathrm{PO}_{4}, 0.17 \%$ dextrose, $\mathrm{pH} 7.2$ ) containing 3 to $5 \times 10^{-6} \mathrm{gm} / \mathrm{ml}$ of curare. To identify polyneuronally innervated muscle fibers, single muscle fibers were impaled by microelectrodes and endplate potentials (epps) were recorded in response to graded stimulation of the motor nerve. In polyneuronally innervated muscle fibers, multiple epps were recorded as increasing stimulus intensity recruited a greater number of axons (see also Brown et al., 1976; Rotshenker, 1979). This method underestimates the incidence of polyneuronal innervation since some thresholds are quite close to another. In addition, poorly transmitting synapses will be missed since the preparations are curarized. In each muscle, 50 to 60 muscle fibers were examined and the incidence of polyneuronal innervation was defined as the percentage of muscle fibers exhibiting multiple epps. The average values were calculated using the individual values from each muscle (average $\pm \mathrm{SEM} ; n=$ number of muscles tested).

Application of horseradish peroxidase (HRP) and its visualization in motor neuron cell bodies. On each experimental day, 4 frogs were anesthetized and the left axillary nerve was treated with either $0.015 \mathrm{M}$ colchicine (2 frogs) or plain Ringer's solution (2 frogs) as described above. Immediately following the colchicine or Ringer treatment, the left cutaneous pectoris muscle was exposed and cut on either side along the length of the nerve. The nerve stump was put into a small "well" made by a small polyethylene ring which was pressed lightly into an Orabase base. The distal half of the stump then was cut and the "well" was filled with a solution of $50 \%$ HRP (w/v, Sigma) prepared in $1 \%$ lysophosphatidyl choline (Sigma). After $1 \mathrm{hr}$, the "well" was removed, the area was rinsed thoroughly with Ringer's solution and the stump was embedded in Silastic (Dow Corning). After the Silastic had vulcanized $(\sim 10 \mathrm{~min})$, the skin was sutured. In order to prevent biasing the results, the HRP applications were performed by a second worker who did not know which treatment (colchicine or Ringer) the animals had received previously.

After $48 \mathrm{hr}$, the frogs were perfused intracardially with $0.1 \mathrm{M}$ phosphate buffer followed by either $1 \%$ glutaraldehyde in $0.1 \mathrm{M}$ phosphate buffer or a solution of $1 \%$ paraformaldehyde, $1 \%$ glutaraldehyde in $0.1 \mathrm{~m}$ phosphate buffer. The section of the spinal cord containing the cervical enlargement was removed, allowed to soak for an additional 1 to $2 \mathrm{hr}$ in the appropriate perfusion solution, and sectioned at $80 \mu \mathrm{m}$ with a Vibratome (Oxford Instruments). The sections were processed for HRP reaction product with tetramethylbenzidine (TMB) according to the procedure of de Olmos et al. (1978). Sections containing labeled neurons were drawn with the aid of a camera lucida and cell counts were made by superimposing the drawings using blood vessels and/or a pinhole through the spinal cord as common reference points.

Visualization of the innervation. The combined silver/cholinesterase method (Pecot-Dechavassine et al., 1979) was used to demonstrate simultaneously nerve endings (silver) and endplate regions (cholinesterase). Whole mounts of muscles were stained and examined in the light microscope at a total magnification of $\times 400$. It was possible to estimate quantitatively the extent of sprouting since most synapses were stained. Muscle fibers were selected for examination if the entire terminal arborization and endplate regions were clearly seen. In each muscle, 30 to 90 muscle fibers were examined and 
the percentage of fibers innervated by both a sprout and a myelinated axon was determined and then used to calculate the average values (average $\pm \mathrm{SEM} ; n=$ number of muscles tested).

\section{Results}

\section{Supernumerary innervation following chemical} axotomy produced by high doses of colchicine

Previous studies (Rotshenker and McMahan, 1976; Rotshenker, 1979; Reichert and Rotshenker, 1979; Rotshenker and Reichert, 1980) revealed the development of a polyneuronal pattern of innervation in the right cutaneous pectoris muscles after injury to the nerve to the left muscles. This altered pattern of innervation was detected anatomically by the identification of the new synapses formed and electrophysiologically by the recording of multiple epps. Axotomy could produce a contralateral pattern of supernumerary innervation by interfering with some trophic interactions between the injured nerve and denervated muscle. To test this hypothesis, I exposed the nerve to the left cutaneous pectoris muscles to colchicine with the aim of inhibiting axonal transport without causing Wallerian degeneration or denervation. These conditions were met when low doses of colchicine $(0.010$ to $0.015 \mathrm{M})$ were used (see the following sections). As expected (Singer and Steinberg, 1972), high doses of colchicine $(0.1 \mathrm{M})$ produced Wallerian degeneration and thus chemical axotomy. The right intact muscles were examined electrophysiologically for supernumerary innervation after chemically axotomizing the nerve to the left muscles at the axilla about midway between the muscle and the spinal cord. The incidence of polyneuronal innervation observed in the right muscles increased over normal to an average value of $33.8 \pm 2.2 \%$ (SEM; $n$ $=8$ ) by 18 days after drug application. Similarly, following surgical axotomy of the left nerve at the same site, supernumerary innervation developed in the right intact muscles 16 days later, averaging $40.5 \pm 4.4 \%$ (SEM; $n=$ 7). Thus, chemical and surgical axotomy produced a contralateral pattern of polyneuronal innervation to the same extent and with the same delay. The timing of the appearance of supernumerary innervation (16 to 18 days) agrees well with my previous observation (Rotshenker, 1979) that the delay with which this altered pattern of innervation developed depended on the distance of the axotomy from the spinal cord such that it became shorter as the site of the axotomy was moved closer to the spinal cord. More than 4 weeks elapsed before supernumerary innervation developed after the nerve was injured close to the muscle (Rotshenker, 1979), about 2.5 weeks passed when the nerve was cut at the axilla (present study), and only 9 days passed when the nerve was severed closer to the spinal cord (Rotshenker, 1979).

\section{Supernumerary innervation produced by low doses of colchicine}

Nerves to the left cutaneous pectoris muscles that were exposed to low doses of colchicine $(0.01$ to $0.015 \mathrm{M}) \mathrm{did}$ not degenerate nor did muscle fibers become denervated. Intramuscular nerve bundles and single fibers were ex- amined routinely for Wallerian degeneration in the light microscope at a total magnification of $\times 200$ in whole mounts of living muscles that were further studied electrophysiologically. All stained preparations (see "Anatomical observations on sprouting and synapse formation") were examined at a total magnification of $x$ 400. In neither case was there evidence for axonal degeneration. The electrophysiological studics further precluded the possibility of denervation since there were no failures in evoking endplate potentials upon nerve stimulation. Wallerian degeneration of a small number axons and electrophysiological evidence for the denervation of a small proportion of muscle fibers were easily detected when higher doses of colchicine were applied to the nerve.

Right cutaneous pectoris muscles that were examined electrophysiologically during the first 18 days after drug application to the left nerves exhibited an incidence of polyneuronal innervation of $16.3 \pm 2.0 \%$ (SEM; $n=9$ ) which is similar to that found in intact muscles of unoperated animals. However, 3 weeks after the operation, the frequency of supernumerary innervation increased more than 2-fold to $38.3 \pm 3.5 \%$ (SEM; $n=7$ ) (Fig. 1). Surprisingly, polyneuronal innervation also developed in the left muscles whose nerves were exposed to the drug. A polyneuronal pattern of innervation was already evident 2 days after the operation and reached $28.0 \pm 1.9 \%$ (SEM; $n=15$ ) (Fig. 1).

Mode of drug application and its role in producing supernumerary innervation. Colchicine might have exerted its effect either locally via the nerve to which it was applied or systemically. Furthermore, sprouting could have resulted solely from the surgical procedures. Two experiments were designed to examine the role of the surgical procedures and the mode of drug application to the development of supernumerary innervation. In the first, only frog Ringer's solution was applied to the left nerves. The incidence of polyncuronal innervation observed 7 to 34 days after the operation was $17.8 \pm 1.5 \%$ (SEM; $n=8$ ) in the left muscles and $17.8 \pm 1.3 \%$ (SEM; $n=8)$ in the right muscles. In the second, colchicine (0.01 to $0.02 \mathrm{M}$ ) was applied $1 \mathrm{~mm}$ away from the nerve but not on top of it. The incidence of polyneuronal innervation detected 7 to 70 days after the operation was $17.2 \pm 1.6 \%$ (SEM; $n=5$ ) in the left muscles and $17.4 \pm$ $2.6 \%$ (SEM; $n=5)$ in the right muscles. Thus, the altered pattern of innervation was produced by colchicine that exerted its effect via the nerve to which it was applied and not after it was distributed systemically.

Retrograde transport of horseradish peroxidase (HRP). We examined the extent to which colchicine produced axonal transport blockade in the left nerves by studying the retrograde transport of HRP. Nerves to the left muscles were exposed at the axilla either to $0.015 \mathrm{M}$ colchicine or Ringer's solution; thereafter, the nerve was cut at the muscle and HRP was applied. Two days later, the spinal cords were sectioned and processed histochemically to demonstrate the enzyme in the cell bodies of the motor neurons. The average number of cells labeled in the drug-treated animals was $4.7 \pm 1.9(\mathrm{SEM} ; n=7)$ per animal, whereas an average of $17.5 \pm 2.8$ (SEM; $n=8$ ) cells were labeled in each of the Ringer-treated frogs. 


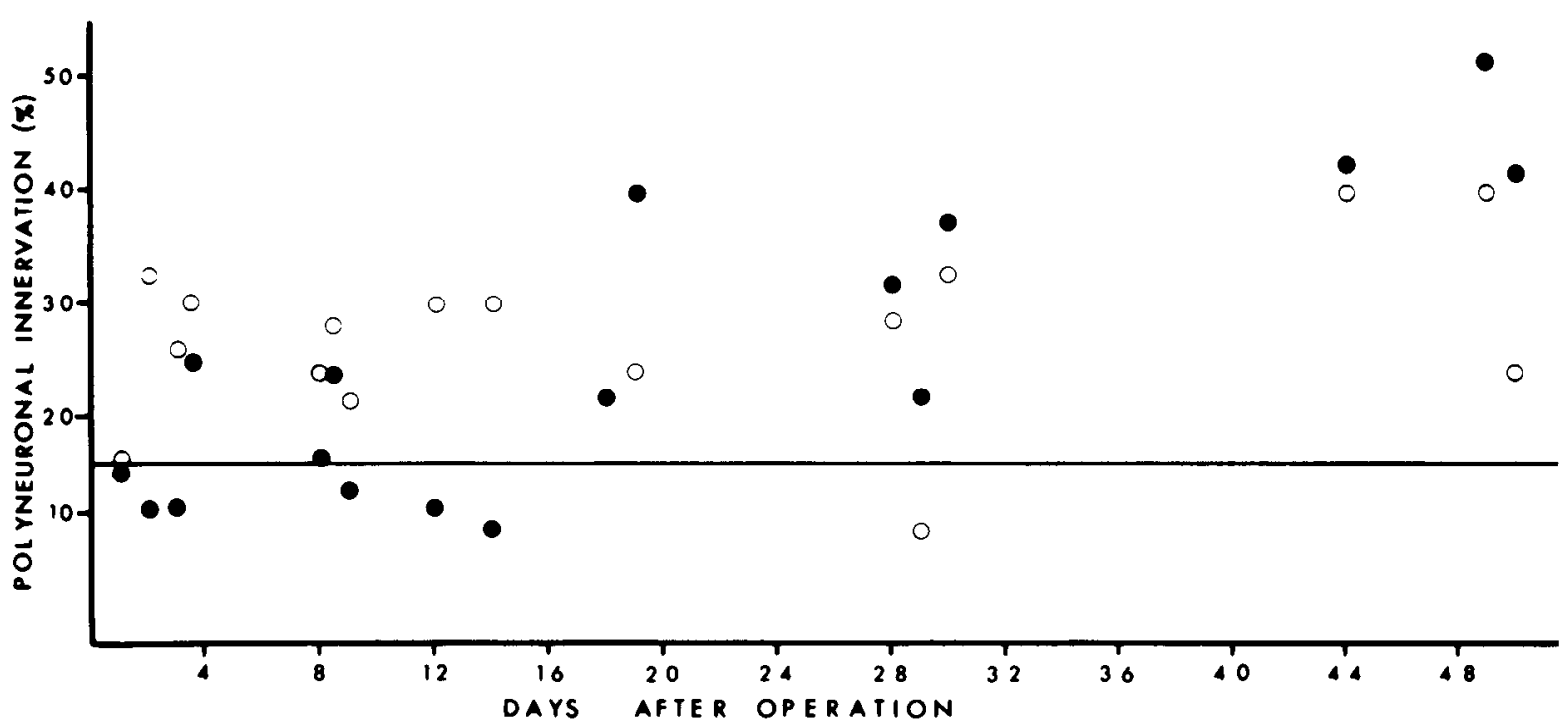

Figure 1. The development of supernumerary innervation in left $(\bigcirc)$ and right $(\bigcirc)$ cutaneous pectoris muscles following the application of 0.01 to $0.015 \mathrm{M}$ colchicine to the nerve to the left muscles at the axilla. Paired muscles of the same frog were examined at each point. In every muscle, 50 to 60 muscle fibers were examined electrophysiologically for polyneuronal innervation and each data point represents the percentage of fibers exhibiting multiple epps. The solid line represents the $\sim 16 \%$ polyneuronal innervation found in the muscles of unoperated frogs.

This result shows that colchicine at the concentrations used partially inhibited the retrograde axonal transport of HRP.

\section{Supernumerary innervation produced by colchicine in muscles whose axons were separated from their cell} bodies

The short latency change in the polyneuronal pattern of innervation in muscles whose nerves were exposed to colchicine raised the possibility that the axons that were exposed to the drug responded by sprouting without mediation through their cell bodies. To test this hypothesis, we examined whether colchicine would produce a similar change in synaptic organization in a muscle whose nerve was isolated from the spinal cord. However, before performing this experiment, it was essential to find out how long after axotomy it would be possible to record epps evoked by stimulation of the nerve close to the muscle distal to the site of axotomy. Cutting the second spinal nerve close to its exit from the spinal column resulted in a failure to produce epps in most muscle fibers by the 4th day after the operation. In the first 3 days, epps were recorded as faithfully as in intact muscles of normal frogs. The incidence of polyneuronal innervation observed 2 and 3 days after the axotomy was $17.5 \pm 1.0 \%$ (SEM; $n=6$ ) in the left muscles and $19.0 \pm 1.6 \%$ (SEM; $n=6$ ) in the right muscles. Thus, degeneration developed at a rate slow enough to enable the examination of the paltern of motor innervation to muscles 2 and 3 days after separating the axons from their cell bodies close to the spinal cord. Colchicine was applied to the left nerves at the axilla several minutes before or after cutting the second left spinal nerve. Left and right cutaneous pectoris muscles were examined 2 and 3 days after the operation. The incidence of polyneuronal innervation detected was $32.4 \pm 2.3 \%$ (SEM; $n=8$ ) in the left muscles and $17.7 \pm$ $1.8 \%(\mathrm{SEM} ; n=8)$ in the right muscles. This indicates a significant $(p<0.005)$ 1.8-fold increase in the incidence of polyneuronal innervation in left muscles whose axons were exposed to colchicine while separated from their cell bodies.

\section{Anatomical observations on sprouting and synapse formation}

Muscles were stained with a combined silver/cholinesterase stain in order to demonstrate simultaneously axon terminals (silver) and endplate regions (cholinesterase). The anatomical pattern of motor innervation to intact muscles of unoperated frogs was similar to that described previously (Letinsky et al., 1976; Letinsky and Morrison-Graham, 1980; Wernig et al., 1980). Most muscle fibers were innervated by single axons that gave rise to several terminal branches that were confined to the muscle fiber innervated at its endplate region. Occasionally, the terminal arborization on one muscle fiber originated from two myelinated axons (Fig. 2), most probably reflecting those muscle fibers which are normally polyneuronally innervated (Letinsky and Morrison-Graham, 1980). Sprouts arising from the nerve endings of one muscle fiber passing to an adjacent muscle fiber were rarely seen in normal frogs $(2.0 \pm 0.4 \%(\mathrm{SEM} ; n=13)$; see also Wernig et al., 1980).

In contrast, in the left muscles whose nerves were separated from their cell body and whose axons were exposed to colchicine 2 to 3 days prior to examination, some axons and nerve endings gave rise to sprouts that left their parent muscle fiber to contact adjacent fibers already innervated by a different axon (Fig. 3). The percentage of muscle fibers showing this latter pattern of innervation was $16.9 \pm 3.6 \%$ (SEM; $n=5)$ in the left muscles and $1.5 \pm 0.6 \%(\mathrm{SEM} ; n=5)$ in the right muscles. Thus, the anatomical and electrophysiological data (see the preceding section) agree well with regard to the additional number of muscle fibers that become polyneu- 
Figures 2 to 5 . The anatomical pattern of the motor innervation to cutaneous pectoris muscle fibers revealed by the combined silver/cholinesterase stain. The stain visualizes axons, nerve terminals, and endplate regions.
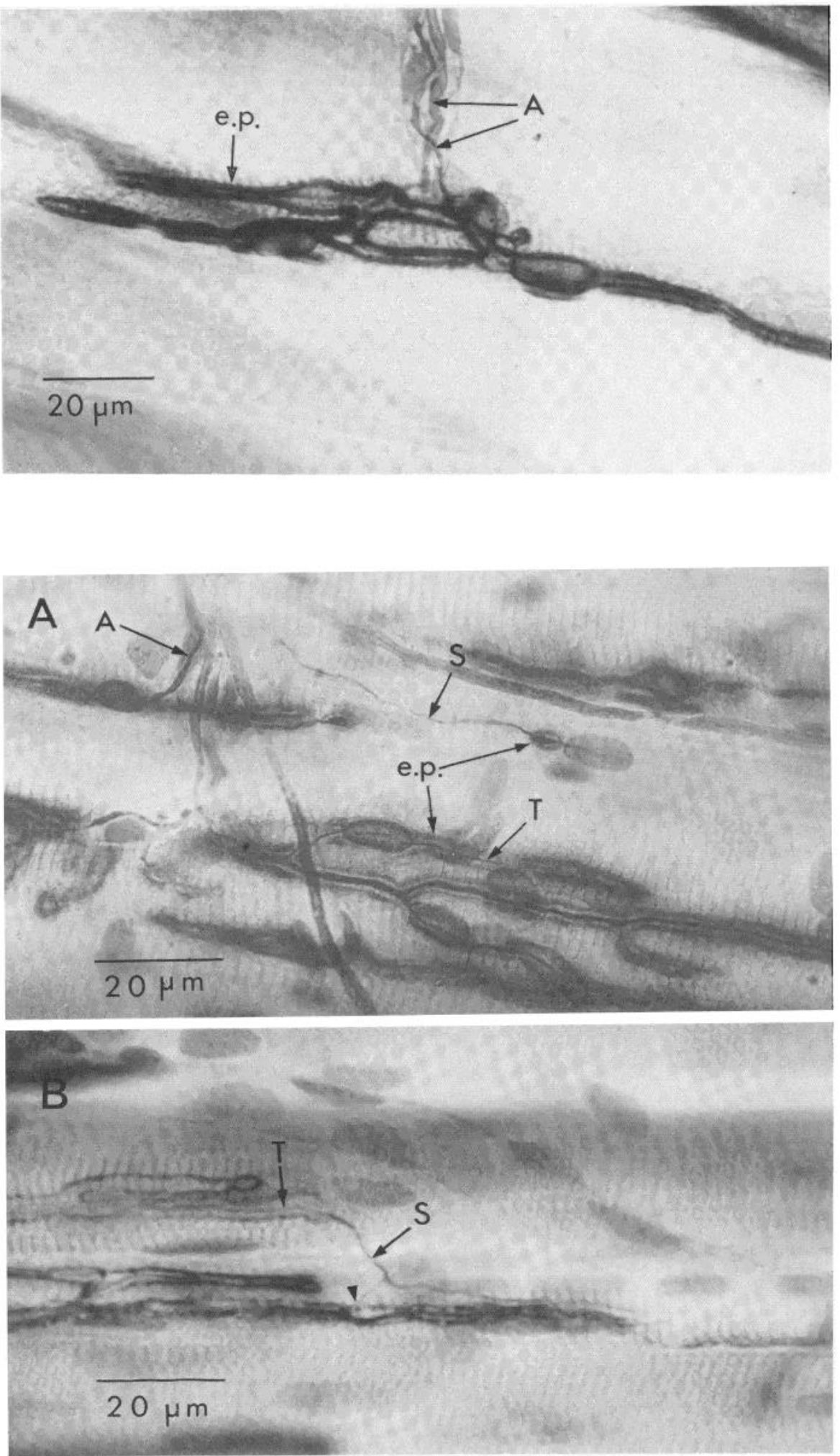

Figure 3. The innervation pattern of muscle fibers 2 days after the nerve to the muscle was separated from the spinal cord and exposed to $0.015 \mathrm{~m}$ colchicine. In panel $A$, the upper muscle fiber is innervated by both an axon $(A)$ and a sprout $(S)$, with which only a small deposit of cholinesterase (e.p.) is associated. In panel $B$, the sprout $(S)$ which arises from the terminal $(T)$ innervating the upper muscle fiber is contributing to the innervation of the adjacent muscle fiber. No deposits of cholinesterase are associated with the sprout which at one point (arrowhead) is probing the existing old endplate. 

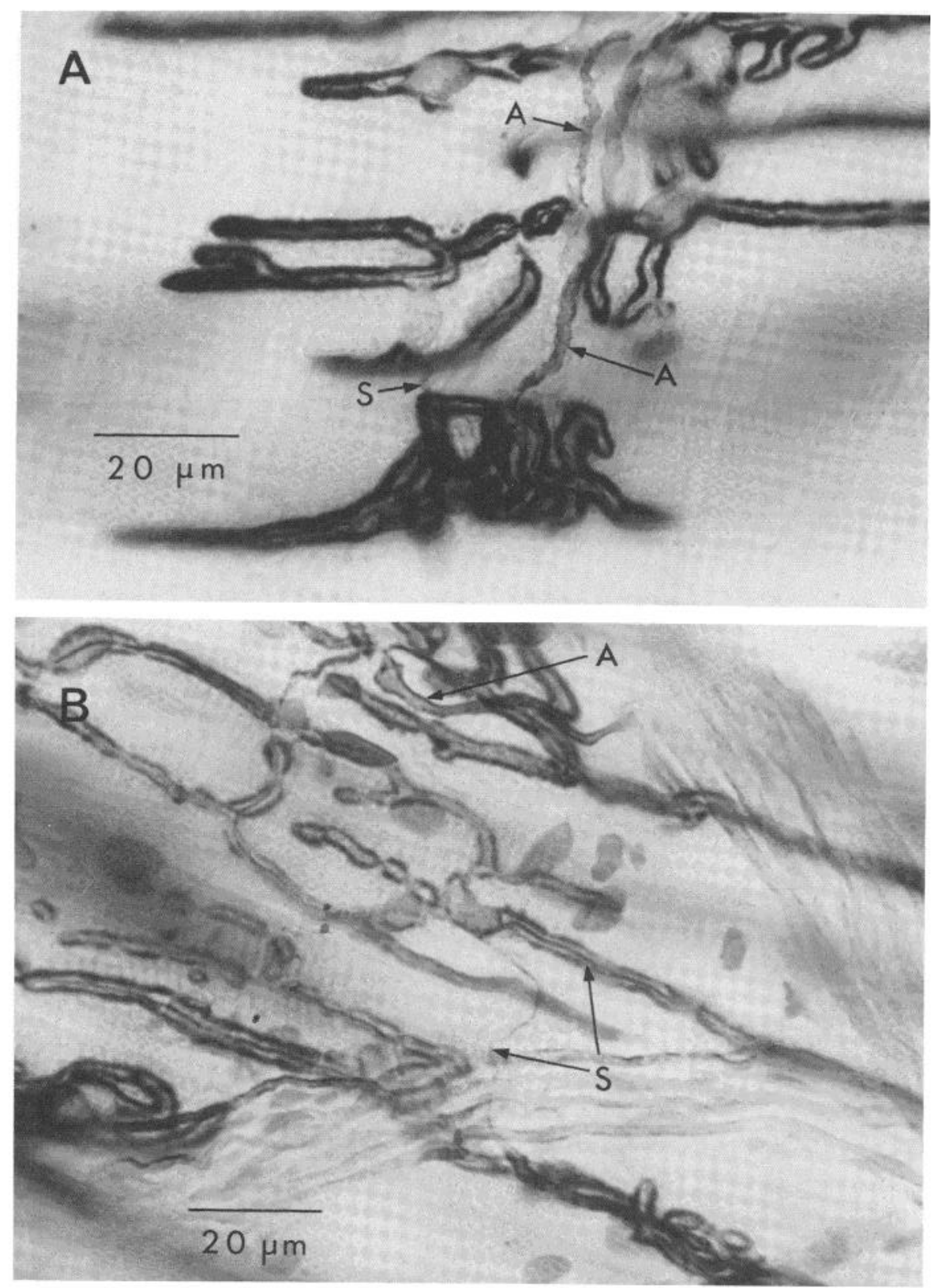

Figure 4. The pattern of innervation of muscle fibers 36 days after the application of $0.015 \mathrm{~m}$ colchicine to the nerve to the left muscle at the axilla. Sprouts $(S)$ are seen in both the left (panel $A$ ) and right (panel $B$ ) muscles. In each case, sprouts $(S)$ that arise from the terminal arborization of one muscle fiber contribute to the innervation of the adjacent already innervated muscle fiber. $A$, Axon.

ronally innervated. Furthermore, the anatomical observations also provide evidence for the timing and site of new synapse formation. It has been shown previously (e.g., Letinsky and Morrison-Graham, 1980; Lomo and Slater, 1981) that the deposition of cholinesterase lags behind the establishment of transmission at newly formed neuromuscular junctions. Finding (Fig. 3) sprouts with which little or no cholinesterase was associated indicates that these are synapses recently formed at new sites. Some of the new junctions also were formed at old sites sine some sprouts were seen to probe and enter established endplate regions (Fig. $3 B$; Fig. 2 in Rotshenker, 1981).
As expected from previous studies (Reichert and Rotshenker, 1979; Rotshenker and Reichert, 1980), sprouting and synapse formation also were observed in the right intact muscles following either axotomy of the left nerve (Fig. 5) or the application of low doses of colchicine to it (Fig. 4). The incidence of muscle fibers that were innervated by both a myelinated axon and a sprout was 23.4 $\pm 1.5 \%$ (SEM; $n=6$, of which 4 were colchicine-treated animals and 2 underwent surgical axotomy). Thus, again, the morphological and electrophysiological data (as discussed earlier) are in good agreement in terms of the number of additional muscle fibers that became polyneuronally innervated. The morphological observations fur- 
ther suggest and support the previous findings (Rotshenker and Reichert, 1980) that new synapses formed in intact muscles can be established at new sites. In Figure 5, for example, one can see a sprout arising from one muscle fiber forming a new young synapse on a neighboring muscle fiber at a new site as judged by the light cholinesterase stain of the new endplate region. Figure 5 also reveals another feature: sprouts also may establish additional contact with their own muscle fibers (see also Fig. 2 in Rotshenker and Reichert, 1980).

\section{Discussion}

The application of low doses of colchicine to nerves innervating the left cutaneous pectoris muscles produced sprouting and synapse formation, and thus, a polyneuronal pattern of innervation, in both left and right muscles. As in previous studies (Rotshenker and McMahan, 1976; Rotshenker, 1979; Reichert and Rotshenker, 1979; Rotshenker and Reichert, 1980), sprouting and synapse formation were assessed electrophysiologically by the recording of multiple epps and morphologically by the identification of the new synapses formed. The development of supernumerary innervation differed greatly between the two muscles with respect to its time of onset following the colchicine application, with delays of only
2 to 3 days in the left muscles and 2.5 to 3 weeks in the right muscles. Furthermore, the short latency response in the left muscles also occurred when the innervating axons were isolated from their cell bodies. These two observations suggest that colchicine produced sprouting of left and right nerves in different ways. This, in turn, suggests that there are two mechanisms by which motor neurons can be induced to sprout: $(a)$ transneuronally, by presenting growth stimuli to the cell body or central processes in the central nervous system and $(b)$ by presenting growth stimuli to the peripheral extensions of the nerve cell.

The transneuronal induction of sprouting and synapse formation (sprouting of motor neurons situated contralateral to the side of colchicine application). The previous observation (Rotshenker and McMahan, 1976; Rotshenker, 1979, 1980; Reichert and Rotshenker, 1979; Rotshenker and Reichert, 1980) that denervation of one cutaneous pectoris muscle of the frog produced sprouting and synapse formation and, thus, a polyneuronal pattern of innervation in the intact homologous muscle on the opposite side led to the suggestion that axotomy initiated a signal for sprouting in the injured nerve cells that transferred transneuronally across the spinal cord to the intact motor neurons innervating the opposite muscle.

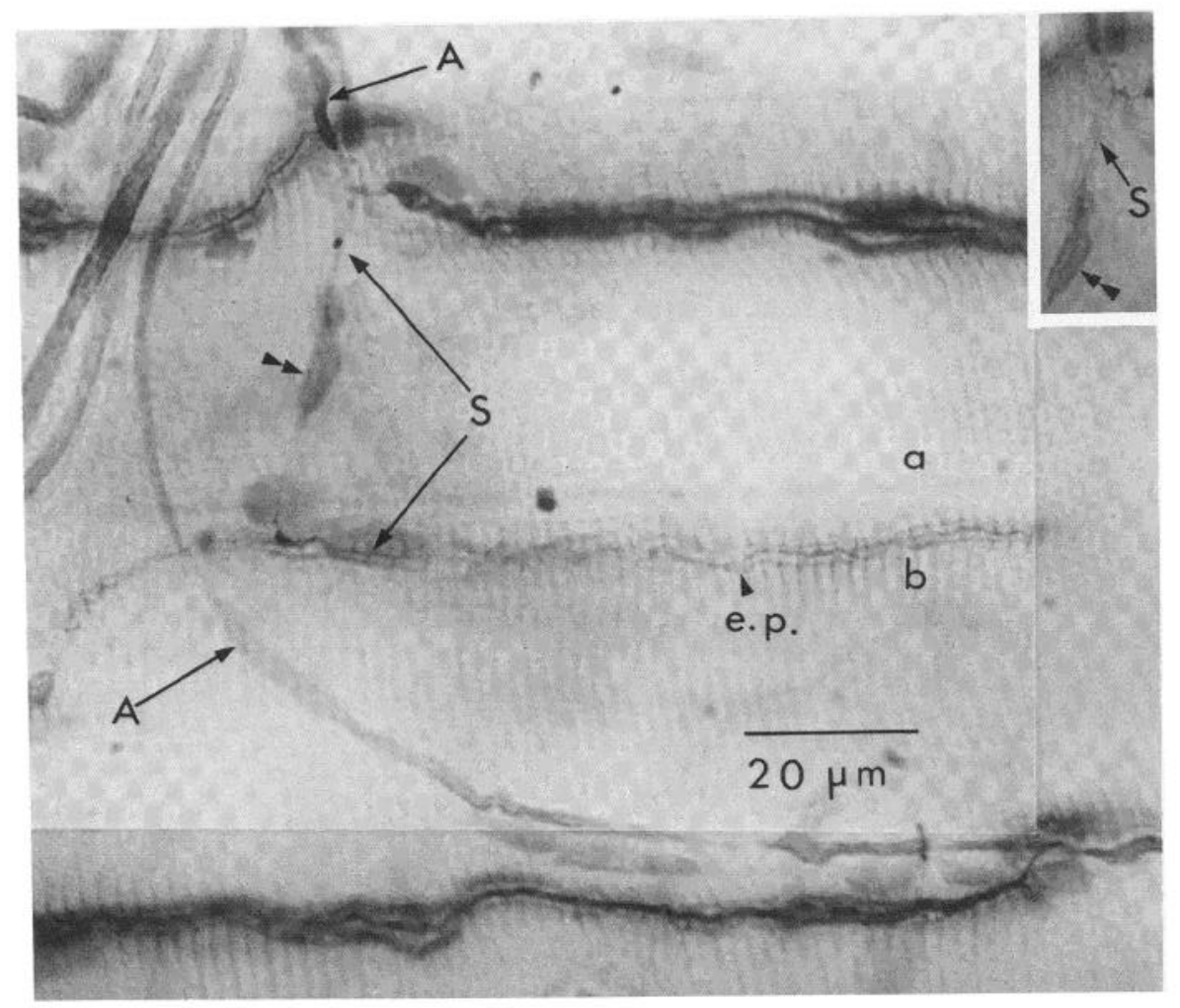

Figure 5. The innervation pattern of the right muscle fibers 15 days after cutting the left brachial nerve close to the spinal cord. Two adjacent muscle fibers, $a$ and $b$, each are innervated by a different axon $(A)$. A sprout $(S)$ arises from muscle fiber $a$ and innervates neighboring muscle fiber $b$. The lightly stained endplate (e.p.; single arrowhead) associated with the sprout suggests that it is a recently formed new site of innervation. The same sprout $(S)$ also forms an additional junctional site on its own muscle fiber ( $a$; double arrowhead). The inset (top right) shows, at a different plane of focus: the sprout $(S)$ as it arises and the additional junctional site on the parent muscle fiber ( $a$; double arrowhead). 
The present study was designed to test the hypothesis that axotomy initiated the signal for sprouting by interfering with some trophic signaling between the injured nerve cells and the denervated muscle. The nerve to the left muscles therefore was exposed to colchicine with the aim of inhibiting axonal transport, on whose integrity trophic interactions depend, without producing either degeneration or denervation. These goals were achieved when low doses of colchicine were used. A marked, although partial, inhibition of the retrograde axonal transport of HRP was obtained, while no signs of degeneration or denervation were detected. In such animals, supernumerary innervation developed in the right muscles with timing and magnitude similar to changes following surgical or chemical axotomy performed at the same site. These data thus suggest that axotomy and colchicine share a common mechanism that produces contralateral sprouting and synapse formation.

Two mechanisms common to colchicine application and axotomy are the inhibition of the retrograde transport of some trophic substance from the periphery of the motor neuron to its cell body and the blockade of the anterograde transport of substances away from the nerve cell body. Similar proposals have been put forward to explain the initiation of retrograde postaxotomy changes in nerve cell bodies (e.g., Grafstein and McQuarrie, 1978; Purves and Lichtman, 1978). Experiments in the superior cervical ganglion provide strong support for the role of the retrograde transport of a trophic substance in regulating retrograde postaxotomy changes. The loss of afferent input to ganglion cells, for example, was produced by either axotomy of the postganglionic nerve (Purves, 1975), the application of colchicine to postganglionic nerve fibers (Purves, 1976), or the administration of antiNGF to the animal (Purves and Nja, 1978). On the other hand, the application of NGF to interrupted axons prevented, to a certain degree, the development of such changes (Nja and Purves, 1978). Alternative mechanisms for the initiation of the signal for contralateral sprouting, for which therc is no evidence at present, are that colchicine enables the entrance of exogenous materials to nerve fibers or that the drug itself produces the signal for sprouting after reaching the neuron's soma.

Alterations in synaptic connectivity following axotomy in regions contralateral and homologous to those that underwent denervation were reported recently. Stefani (E. Stefani, manuscript in preparation) observed a 5 -fold increase $(22 \%$ versus $4 \%)$ in the percentage of twitch muscle fibers comprising the piriformis muscle of the frog that became polyneuronally innervated after cutting the innervation to the opposite muscle. Interestingly, few of the slow muscle fibers became hyperinnervated by the sprouting fast motor neurons. This altered pattern of innervation was detected by the recording of multiple epps in uncurarized or slightly curarized preparations. In the cat (Steinbach, 1981), interruption of the sciatic nerve in one hindlimb was followed by an increase in synaptic size in fast twitch muscles (peroneus tertius and extensor digitorum longus) but not in slow twitch muscles (soleus) situated in the contralateral intact hindlimb. A similar observation also has been made in mice (Brown el al., 1980), where after cutting the innervation to one hind- limb, there was an increase, although small, in the incidence of sprouting in the contralateral fast twitch peroneus tertius muscle but not in the slow twitch soleus muscle.

Alteration in synaptic connectivity also was observed in systems other than the motor system. Bilateral synaptic changes involving the small granule-containing cells in rat superior cervical ganglion were observed following axotomy of the postganglionic fibers on one side (Case and Matthews, 1980). In the young rat dentate gyrus (Hoff et al., 1981), lesion to the entorhinal cortex that innervates the outer two-thirds of the molecular layer was followed by complex synaptic changes in the inner one-third of the ipsilateral and of the entire contralateral molecular layer. In contrast to the reports that indicate structural and functional changes following contralateral axotomy, a study in the sartorius muscle of the frog (Herrera and Grinell, 1981) suggests only functional changes of increased synaptic efficacy to explain the electrophysiologically observed increase in supernumerary innervation since no sprouts were detected histochemically (see, however, Weakly and Yao (1981) who did not observe similar functional changes). Recent anatomical studies in this laboratory (G. Ring, F. Reichert, and $\mathrm{S}$. Rotshenker, manuscript in preparation) do reveal the presence of sprouts in intact sartorius muscles following contralateral axotomy.

Synaptic changes that occur in regions homologous and contralateral to the site of axotomy (see above) indicate a lateral or commissural transneuronal pathway for the induction of synaptic changes. Transneuronal alterations in synaptic arrangements may take other directions as well. For example, an anterograde transneuronal induction of sprouting was described in the visual system (LeVay et al., 1980). Reopening of an unexperienced eye and closing the other eye produced sprouting in part of the geniculocalcarine tract driven by the previously deprived eye. A retrograde transneuronal induction of sprouting also was described. In the cat, crossinnervation of muscles in the forelimb resulted in sprouting of the cortical projection to red nucleus cells (Tsukahara, 1978)

Whether all transneuronal synaptic changes share common or different mechanisms is not known. It is clear that the transneuronal induction of synaptic alterations offers a mechanism by which single cells that are part of a functional pathway may influence the field of innervation of other cells within the same or counterpart pathways. Such a mechanism could play an important role in the proper development of pathways and their modification upon insult during development and in the adult.

The peripheral induction of sprouting (sprouting of axons that were exposed to colchicine). Sprouting and synapse formation occurred in the left muscles 2 days after the application of colchicine to nerves that were either intact or separated from the spinal cord. The ability of colchicine to induce neurite outgrowth, of axons that were separated from their cell bodies to elongate, and of synapses to form rapidly was described previously. A low dose of colchicine initiated growth cone formation in cultured neurons (Bray et al., 1978) and sprouting and synapse formation in the rat dentate gyrus (Goldowitz 
and Cotman, 1980). Axons that were separated from their cell bodies and grew before undergoing subsequent degeneration were observed in chick brain, spinal cord, and dorsal root ganglia cultures (Levi and Meyer, 1945; Hughes, 1953; Shaw and Bray, 1977). Finally, the time interval of 2 days during which new synapses were formed in cutaneous pectoris muscles following colchicine application is similar to the 1- to 3-day time interval required for the development of ectopic synapses in muscles by preimplanted nerves after axotomy of the original nerve or after poisoning the muscle with botulinum toxin (Fex and Thesleff, 1967; Lomo and Slater, 1981; Tonge, 1977).

In what way did colchicine induce the growth of axons that were exposed to it? It has been suggested previously that colchicine may induce intact nerve fibers to sprout as a consequence of the blockade of axonal transport in neighboring nerve fibers (Aguillar et al., 1973; Guth et al., 1980). A similar situation can be postulated in the present experiments since colchicine may have reduced axonal transport in some of the axons that comprise the nerve to the cutaneous pectoral muscle and thereby induce the sprouting of the unaffected fibers. The observation that axons isolated from their cell bodies do not sprout unless they also are exposed to colchicine presents some difficulty in adopting this hypothesis to thr $\mathrm{se} a \mathrm{x}-$ perimental conditions since axotomy that interferes with axonal transport in some of the axons that comprise the nerve to the cutaneous pectoris muscle and thereby tion of colchicine.

Another possible mechanism by which colchicine could induce sprouting of axons that were exposed to it is by altering the responsiveness of the nerve fiber to an existing stimulus for growth which, under normal conditions, is subthreshold. Colchicine could do so by affecting some cytoskeletal elements that normally have a repressive effect on neurite motility and/or neurite responsiveness to growth stimulants. A number of observations that were made in neuronal and other systems support this hypothesis. Low doses of antimicrotubular agents induced growth cone formation in cultured neurons (Bray et al., 1978) and locomotor activity in fibroblasts (Vasiliev et al., 1970, 1971). Antimicrotubular agents also modulated the rate of intact motor axon sprouting in partially denervated muscles (Hoffman, 1952); low doses of cryptopleurine accelerated sprouting, whereas high doses retarded it. Colchicine that was used in only one dose enhanced sprouting in some animals and inhibited it in others. Low doses of colchicine were further shown to be synergistic with mitogens in that colchicine enabled otherwise subthreshold concentrations of growth stimulants (mitogens) to induce DNA synthesis in cultured fibroblasts (Vasiliev et al., 1971; Teng et al., 1977; Friedkin et al., 1979; Otti et al., 1979; McClain and Feldman, 1980).

Thus, it is possible that colchicine made axons responsive to a subthreshold stimulus for growth. The existence of substances that are synthesized and released by target cells and have a growth-promoting influence on their innervating nerve fibers has been long suggested to occur during development (Ramon y Cajal, 1960). The recent observation (Ebendal et al., 1980) that denervated irides produce such substances strongly supports this hypoth- esis. It is thus conceivable that, in the adult animal, a dynamic state of growth equilibrium is achieved due to a reduced synthesis and release of growth stimulants on behalf of the target and a reduced responsiveness in part of the innervating nerve fibers. Based on such a scheme, one would expect intact nerve fibers to sprout when their target cells produce and release larger than normal amounts of growth-promoting substances and/or when nerve fibers become more responsive to such factors.

\section{References}

Aguillar, C. E., M. A. Bisby, E. Cooper, and J. Diamond (1973) Evidence that axoplasmic transport of trophic factors is involved in regulation of peripheral nerve fields in the salamander. J. Physiol. (Lond.) 234: 449-464.

Bray, D., C. Thomas, and G. Shaw (1978) Growth cone formation in cultures of sensory neurons. Proc. Natl. Acad. Sci. U. S. A. 75: 5226-5229.

Brown, M. C., R. L. Holland, and R. Ironton (1980) Nodal and terminal sprouting from motor nerve in fast and slow muscles of the mouse. J. Physiol. (Lond.) 306: 493-510.

Brown, M. C., J. K. S. Jansen, and D. Van Essen (1976) Polyneuronal innervation of skeletal muscle in new-born rats and its elimination during maturation. J. Physiol. (Lond.) 261: $387-422$.

Case, C. P., and M. R. Matthews (1980) Bilateral synaptic changes involving small granule containing (SG) cells in the rat superior cervical ganglion after unilateral postganglionic axotomy. J. Physiol. (Lond.) 301: 57 p.

Cull, R. E. (1975) Role of axonal transport in maintaining central synaptic connections. Exp. Brain Res. 24: 97-101.

de Olmos, J., H. Hardy, and L. Heimer (1978) The afferent connections of the main and accessory olfactory bulb formation in the rat: An experimental study. J. Comp. Neurol. 181: 213-244.

Ebendal, T., L. Olson, A. Seiger, and K. O. Heduldund (1980) Nerve growth fractor in the rat iris. Nature 286: 25-28.

Fex, S., and S. Thesleff (1967) The time required for innervation of denervated muscles by nerve implants. Life Sci. 6: 635639.

Friedkin, R., A. Legg, and E. Rozengurt (1979) Antitubulin agents enhance stimulation of DNA synthesis by polypeptide growth factors in 3T3 mouse fibroblasts. Proc. Natl. Acad. Sci. U. S. A. 7: 3909-3912.

Goldowitz, D., and C. W. Cotman (1980) Do neurotrophic interactions control synapse formation in the adult brain? Brain Res. 181: 325-344.

Grafstein, B., and I. G. McQuarrie (1978) The role of the nerve cell body in axonal regeneration. In Neuronal Plasticity, C.W. Cotman, ed., pp. 155-196, Raven Press, New York.

Guth, L., S. Smith, E. J. Donati, and E. X. Albuquerque (1980) Induction of intramuscular collateral nerve sprouting by neurally applied colchicine. Exp. Neurol. 67: 513-523.

Herrera, A. A., and A. D. Grinell (1981) Contralateral denervation causes enhanced transmitter release from frog motor nerve terminals. Nature 291: 495-497.

Hoff, S. F., S. W. Scheff, A. Y. Kwan, and C. W. Cotman (1981) A new type of lesion induced synaptogenesis: I. Synaptic turnover in nondenervated zones of dentate gyrus in young adult rats. Brain Res. 222: 1-13.

Hoffman, H. (1952) Acceleration and retardation of the process of axon-sprouting in partially denervated muscles. Aust. J. Exp. Biol. Med. Sci. 30: 541-566.

Hughes, A. (1953) The growth of embryonic neurites. J. Anat. 87: $150-164$

Letinsky, M., and K. Morrison-Graham (1980) Structure of 
developing frog neuromuscular junction. J. Neurocytol. 9: 321-342.

Letinsky, M., K. Fishbeck, and U. J. McMahan (1976) Precision of reinnervation of original postsynaptic site in frog muscle after a nerve crush. J. Neurocytol. 5: 691-718.

LeVay, S., 'T' N. Wiesel, and D. H. Hubel (1980) 'The development of ocular dominance columns in normal and visually deprived monkeys. J. Comp. Neurol. 191: 1-51.

Levi, G., and H. Meyer (1945) Reactive, regressive and regeneration processes of neurons cultivated in vitro and injured by micromanipulation. J. Exp. Zool. 99: 141-181.

Lomo, T., and C. R. Slater (1981) Control of junctional and acetylcholinesterase by neural and muscular influences in the rat. J. Physiol. (Lond.) 303: 191-202.

McClain, D. A., and G. M. Feldman (1980) Density-dependent stimulation and inhibition of cell growth by agents that disrupt microtubules. Proc. Natl. Acad. Sci. U. S. A. 77: 27482752.

Nja, A., and D. Purves (1978) The effect of nerve growth factor and its antiserum on synapses in the superior cervical ganglion of the guinea pig. J. Physiol. (Lond.) 277: 53-75.

Otti, M. A., A. Zumbe, L. Gibson, A. M. Kubler, and L. Jimenez de Asuel (1979) Cytoskeleton disrupting drugs enhance effect of growth factors and hormones on initiation of DNA synthesis. Proc. Natl. Acad. Sci. U. S. A. 12: 6435-6438.

Pecot-Dechavassine, M., A. Wernig, and H. Stover (1979) A combined silver and cholinesterase method for studying exact relations between the pre and the postsynaptic elements at the frog neuromuscular junction. Stain Technol. 54: 25-28.

Pilar, G., and L. Landmesser (1972) Axotomy mimicked by localized colchicine application. Science 177: 1116-1118.

Purves, D. (1975) Functional and structural changes in mammalian sympathetic neurons following interruption of their axons. J. Physiol. (Lond.) 252: 429-463.

Purves, D. (1976) Functional and structural changes in mammalian sympathetic neurons following colchicine application to post ganglionic nerves. J. Physiol. (Lond.) 259: 159-175.

Purves, D., and W. J. Lichtman (1978) Formation and maintenance of synaptic connections in autonomic ganglia. Physiol. Rev. 58: 821-862.

Purves, D., and A. Nja (1978) Trophic maintenance of synaptic connections in autonomic ganglia. In Neuronal Plasticity, C. W. Cotman, ed., pp. 27-42, Raven Press, New York.

Ramon y Cajal, S. (1960) Studies on Vertebrate Neurogenesis, L. Guth, translator, pp. 149-200, Springfield.

Reich $\epsilon_{\perp} t, F$., and S. Rotshenker (1979) motor axon sprouting in intact muscles. Brain Res. 170: 187-189.

Rotshenker, S. (1979) Synapse formation in intact innervated cutaneous-pectoris muscles of the frog following denervation of the opposite muscle. J. Physiol. (Lond.) 292: 535-547.

Rotshenker, S. (1980) The transneuronal induction of sprouting and synapse formation. In Regulatory Functions of the CNS, J. Szentagothai, J. Hamori, and M. Palkovits, eds., Vol. 2, pp. 22-45, Pergamon Press, Elmsford, NY.

Rotshenker, S. (1981) Sprouting and synapse formation by motor axons separated from their cell bodies. Brain Res. 223: 141-145.

Rotshenker, S., and U. J. McMahan (1976) Altered patterns of innervation in frog muscle after denervation. J. Neurocytol. 5: $719-730$.

Rotshenker, S., and F. Reichert (1980) Motor axon sprouting and site of synapse formation in intact innervated skeletal muscle of the frog. J. Comp. Neurol. 193: 413-422.

Shaw, G., and D. Bray (1977) Movement and extension of isolated growth cones. Exp. Cell Res. 104: 56-62.

Singer, M., and M. C. Steinberg (1972) Wallerian degeneration: A reevaluation based on transected and colchicine poisoned nerves in the amphibian, Triturus. Am. J. Anat. 133: 51-84.

Steinbach, H. J. (1981) Neuromuscular junctions and $\alpha$-bungarotoxin binding sites in denervated and contralateral cat skeletal muscles. J. Physiol. (Lond.) 313: 513-528.

Teng, M., J. C. Bartholomew, and M. J. Bissel (1977) Synergism between antimicrotubule agents and growth stimulants in enhancement of cell cycle traverse. Nature 268: 739-791.

Tonge, D. A. (1977) Effect of implantation of an extra nerve on the recovery of neuromuscular transmission from botulinum toxin. J. Physiol. (Lond.) 265: 809-820.

Tsukahara, N. (1978) Synaptic plasticity in the red nucleus. In Neuronal Plasticity, C. W. Cotman, ed., pp. 113-130, Raven Press, New York.

Vasiliev, J. M., M. I. Gelfand, L. V. Domina, O. Y. Ivanova, S. G. Komn, and L. V. Olshevskaja (1970) The effect of colcemid on the locomotory behavior of fibroblasts. J. Embryol. Exp. Morphol. 21: 625-640.

Vasiliev, J. M., M. I. Gelfand, and V. I. Guelstein (1971) Initiation of DNA synthesis in cell cultures by colcemid. Proc. Natl. Acad. Sci. U. S. A. 68: 977-979.

Weakly, J. N., and Y. M. Yao (1981) Section of lumbar spinal roots fails to induce synapse formation in contralateral, innervated sartorius muscles of the frog. Brain Res. 204: 421423.

Wernig, A., M. Pecot-Dechavassine, and H. Stover (1980) Sprouting and regression of the nerve at the frog neuromuscular junction to normal conditions and after prolonged paralysis by curare. J. Neurocytol. 9: 277-303. 